\title{
O tratamento da oralidade no programa nacional do livro didático 2019 : o que muda em relação às edições anteriores?
}

The orality treatment in the national teaching book 2019 program: what changes in relation to previous editions?

\author{
Estephane Priscilla dos Santos Mendes \\ Universidade Federal de Pernambuco - UFPE \\ Ana Cláudia Rodrigues Gonçalves Pessoa \\ Universidade Federal de Pernambuco - UFPE \\ DOI: https://doi.org/10.5902/2176148539536
}

\begin{abstract}
Resumo: Este artigo tem como objetivo analisar como se apresenta o eixo de ensino oralidade no PNLD 2019 e quais as principais mudanças do Guia 2019 em relação às edições anteriores, no que concerne ao trabalho com o oral nos Livros Didáticos destinados aos anos iniciais do Ensino Fundamental. Adotamos como procedimento metodológico a pesquisa documental. Os resultados deste estudo apontaram que os critérios presentes no Guia 2019 não trazem nenhuma grande inovação ou avanço no que concerne ao eixo oralidade.
\end{abstract}

Palavras-chave: Oralidade. PNLD. Livros Didáticos.

Abstract: The purpose of this article is to analyze orality teaching as it is presented in the PNLD 2019, as well as which are the main changes in the Guia 2019 in relation to its previous editions, regarding the orality work in textbooks intended for Elementary School early years. We adopted as methodological procedure the documentary research. The results of this study indicated that the criteria present in Guia 2019 do not bring any major innovation or advance regarding orality.

Keywords: Orality. PNLD. Textbooks. 


\section{Introdução}

A oralidade está presente nas salas de aula em diferentes situações (na rotina cotidiana, na correção de exercícios, na contação de histórias, nas Estephane conversas informais, dentre outras). Entretanto, pesquisas (cf. DOLZ e

Priscilla dos Santos Mendes

Ana Cláudia

Rodrigues

Gonçalves

Pessoa
SCHNEUWLY, 2004; LEAL, BRANDÃO e LIMA, 2012; ÁVILA, NASCIMENTO e GOIS, 2011; COSTA-MACIEL e BARBOSA, 2012; BOTLER, 2013) apontam que, na maior parte das aulas, ela não é tomada como objeto de ensino, o que nos leva a concluir que "o ensino escolar da língua oral e de seu uso ocupa atualmente um lugar limitado" nas salas de aula do ensino básico (DOLZ e SCHNEUWLY, 2004, p. 125).

Se a oralidade está tão presente na vida cotidiana das crianças, caberia à escola incentivá-las a fazer novas descobertas acerca dessa prática que elas usam constantemente, permitindo-as utilizar a língua oral em contextos que ainda não são familiares. Nesse sentido, a escola pode contribuir com o processo de ensino-aprendizagem das crianças ao ensinar certos usos mais formais e públicos da oralidade, auxiliando a criança a compreender que diferentes situações exigem um maior ou menor monitoramento da fala. Entretanto, o que se percebe é que, nas salas de aula, o oral aparece quase sempre a serviço da escrita. Assim, em muitos casos, o oral é trabalhado, principalmente, como meio para a aprendizagem da produção escrita e da fluência em leitura.

Ao longo dos anos, muitas alterações ocorreram em relação aos livros didáticos, muitas delas decorrentes dos avanços de concepção de língua, de ensino, de aprendizagem, dentre outros. Essas mudanças também foram, em parte, impulsionadas pelo processo de avaliação e aquisição de livros didáticos pelo governo. As exigências postas nos editais de avaliação tendem a induzir o mercado editorial a investir na qualidade do material a ser oferecido nas escolas. Por isso, desenvolveremos aqui uma breve discussão sobre a oralidade no PNLD.

De acordo com Mantovani (2009), a preocupação do Estado com o livro didático brasileiro teve início há bastante tempo, com a criação do Instituto Nacional do Livro Didático (INL), em 1929. Segundo essa autora, foi através desse órgão que começaram a se estreitar as relações entre o governo e as obras didáticas. Na década de 1930, mais precisamente em 1938, por meio do Decreto-Lei no 1.006, de 30/12/38, foi instituída a Comissão Nacional do Livro Didático (CNLD), estabelecendo uma primeira política de legislação e controle de produção e circulação do 
livro didático no país ${ }^{1}$. Ainda segundo Mantovani (2009, p. 27), "entre as responsabilidades da CNLD estavam examinar, avaliar e julgar os livros didáticos, concedendo ou não autorização para o seu uso nas escolas". No entanto, conforme essa autora, essa comissão não examinava a qualidade dos livros, preocupando-se apenas com a adequação ou não aos programas oficiais de ensino.

Atualmente, o Programa Nacional do Livro Didático (PNLD) tem sido responsável pela aquisição do livro didático, além de outros materiais. Esse programa não é recente, e passou por inúmeras modificações ao longo dos anos. No que se refere ao PNLD de Alfabetização/ Língua Portuguesa, foco desse estudo, essas mudanças foram tanto de origem estrutural, quanto de concepção de ensino da língua materna. Nesse sentido, é nosso objetivo analisar como se apresenta o eixo de

O tratamento da oralidade no programa nacional do livro didático 2019 ensino oralidade no PNLD 2019. Especificamente, buscamos analisar os critérios de avaliação da oralidade nos livros didáticos destinados aos anos iniciais do Ensino Fundamental; identificar o espaço dado ao tratamento da oralidade no Guia 2019; analisar o conceito de ensino do oral veiculado pelo PNLD 2019 e, finalmente, identificar as principais mudanças do Guia 2019 em relação às edições anteriores no que concerne ao trabalho com o oral nos Livros Didáticos. Para atender aos objetivos supracitados, realizamos uma análise documental do Guia de Livros Didáticos do PNLD 2019.

Iniciaremos nossa discussão, apresentando pesquisas que tratam do ensino de oralidade nas salas de aulas da Educação Básica. Em seguida, apresentaremos um breve histórico do PNLD e a caracterização dos Guias de LDs do referido programa, sua organização e estrutura. Por fim, discutiremos a presença do eixo oralidade no Guia 2019, trazendo os resultados de nosso estudo, através da apresentação e análise dos dados.

\section{A oralidade nas salas de aula: o que nos apontam as pesquisas?}

Nessa seção, discutiremos pesquisas empíricas que tratam da oralidade e de seu ensino, buscando compreender como os docentes têm tratado o ensino do oral e como o livro didático tem sido visto nesse processo.

1 Informações retiradas de <http://www.fnde.gov.br/programas/livro-didatico/livro-didatico-apresentacao>. Acesso em: 10 jan. 2016. 
Para iniciarmos a discussão, convém ressaltar que o ensino do oral está baseado na concepção do que é o oral e qual oral se deve ensinar na escola. Para Schneuwly (2004), o oral que deve ser tratado na

Estephane

Priscilla dos Santos Mendes

Ana Cláudia

Rodrigues

Gonçalves

Pessoa escola é aquele da esfera pública, ou seja, aqueles gêneros orais que exigem antecipação e planejamento. Esse mesmo autor realizou uma pesquisa com professores-estudantes de Ciências da Educação com o objetivo de identificar quais eram as representações habituais do oral e de seu ensino para esses docentes. Para atender a esse objetivo, os participantes foram instados a responder ao seguinte questionamento: "você é professor(a) (ou imagina ser). No programa está previsto o ensino do oral (expressão e compreensão). O que é oral pra você? Responda em cerca de dez linhas" (SCHNEUWLY, 2004, p. 110). A partir de cerca de 25 respostas, o autor pôde concluir que, para esses professores-estudantes, o oral é percebido enquanto lugar de espontaneidade e liberação, não se constituindo como algo possível de ser ensinado. Na visão desses sujeitos pesquisados, o oral que se aprende na escola é o oral da escrita, aquele que prepara para a escrita, ou seja, a oralização do escrito. Nesse sentido, o referido autor enfatiza a necessidade de definição da concepção de oralidade utilizada para fundamentar o ensino.

Desse modo, para que exista um ensino que leve o aluno a dominar sua língua em situações comunicativas diversas, a concepção de oralidade deve ser rica e complexa, compreendendo o oral em relação dialética com a escrita. Sabemos que o ensino da oralidade ainda é recente quando comparado aos demais eixos de ensino da língua portuguesa. Ao observar-se a prática de docentes em relação ao oral, percebe-se um trabalho mais voltado para a oralização da escrita ou situações mais cotidianas, como as rodas de conversa, por exemplo. Porém, para que o aluno domine o oral em situações comunicativas diversas, é importante desenvolver um trabalho com gêneros orais distintos.

A partir dessa compreensão, Celestino et al. (2007) realizaram um estudo com o objetivo de identificar quais gêneros orais da ordem do argumentar eram explorados durante as aulas do $2^{\circ}$ ano do $2^{\circ}$ ciclo de escolas públicas da cidade do Recife - $\mathrm{PE}$, e se havia um investimento das docentes em tais atividades. Ao todo, foram investigadas as práticas docentes de 5 (cinco) professoras, sendo observadas 15 (quinze) aulas de cada. Os dados apontaram ausência de um trabalho que envolvesse o eixo da oralidade de modo planejado e sistemático em sala de aula. Os gêneros textuais produzidos pelos alunos nestas aulas foram, via de 
regra, conversa informal e discussão. Desse modo, os estudantes não eram estimulados, de fato, a desenvolver capacidades argumentativas demandadas em outros tipos de situações sociais.

Ainda na mesma linha de pesquisa, Celestino e Leal (2008) demonstraram que o trabalho com sequência didática envolvendo o gênero debate, por exemplo, é uma possibilidade interessante de trabalho dinâmico no espaço escolar e pode ultrapassar os muros da escola. A referida pesquisa consistiu em analisar o desenvolvimento de uma sequência didática voltada para o ensino do gênero textual debate em aulas em que foi abordado um tema do componente curricular "História: relações de gênero". A sequência foi desenvolvida por uma professora do $2^{\circ}$ ciclo que estava participando de um programa de formação continuada, desenvolvida pelo grupo de estudo e de pesquisa "Argumentação e Ensino”, da Universidade Federal de Pernambuco.

De acordo com as autoras, durante o debate, os alunos se apropriaram mais do elemento de retomada da fala do outro para justificar seu ponto de vista, o que é uma característica importante do gênero, além de outros aspectos característicos do gênero, como o respeito durante a fala do outro e a regulação do tempo, elementos que foram bastante enfatizados pela professora ao longo da sequência didática.

Estudos que abordam o oral no livro didático e as relações desse material com as orientações presentes no PCN de Língua Portuguesa ou em outras diretrizes confirmam que o oral aparece constantemente a serviço do escrito, não se constituindo, em muitos casos, enquanto objeto de ensino, e, embora haja no PCN indicações claras das dimensões de ensino do oral a serem contempladas, estas não aparecem de forma efetiva nas atividades propostas pelos Livros didáticos (ROJO e BATISTA, 2003; MARCUSCHI, 2005; COSTA-MACIEL, 2006; MAGALHÃES, 2007; LEAL e GOIS, 2012; DUTRA, 2013; SANTOS, 2013; SOUSA-MACHADO, 2013).

\section{Breve Histórico do Programa Nacional do Livro Didático}

Em 1996, o MEC passou a desenvolver algumas medidas para avaliar o livro didático de forma sistemática, por meio de critérios previamente discutidos e estabelecidos pelo próprio Ministério, obtendo como resultado desse processo a primeira publicação do "Guia de Livros Didáticos" de $1^{\text {a }}$ a $4^{a}$ série. Embora parte significativa desses critérios avaliativos estivesse relacionada às diferentes áreas do conhecimento as quais os livros se destinavam, alguns critérios eram comuns, como, por exemplo, a adequação 
Estephane

Priscilla dos Santos Mendes

Ana Cláudia

Rodrigues

Gonçalves

Pessoa didática e pedagógica, a qualidade editorial e gráfica, a pertinência do manual do professor para o auxílio na utilização do livro didático, dentre outros (BATISTA, 2003). Assim, "na avaliação dos LDs [livros didáticos] há critérios eliminatórios comuns a todas as áreas, e também critérios classificatórios específicos a cada uma delas" (COSTA VAL, 2009, p. 14). Além disso, eram eliminados da avaliação livros que apresentassem erros conceituais, indução a erros, desatualização, preconceito ou discriminação de qualquer tipo (BATISTA, 2003; COSTA VAL, 2009).

Os primeiros resultados dessa avaliação foram divulgados em 1996 através do Guia, conforme dissemos anteriormente. Nessa edição do PNLD, os livros foram classificados em quatro grandes categorias (BATISTA, 2003; MANTOVANI, 2009): excluídos; não-recomendados; recomendados com ressalvas; e recomendados. No PNLD 1997, surgiu a menção "recomendada com distinção", bem como a utilização de um sinal gráfico, representado por estrelas (3 estrelas - recomendado com distinção; 2 estrelas - recomendado; 1 estrela - recomendado com ressalvas). Nos PNLD de 2000/2001, 2002 e 2004, as obras foram assim classificadas: recomendada com distinção (RD), recomendada (R), recomendada com ressalvas (RR) e excluída. No PNLD 2004, já não havia a sinalização gráfica das estrelas e, a partir do PNLD 2005, a nomenclatura foi simplificada, com as designações de recomendado (aprovado) ou não recomendado (não aprovado) (ALVES, 2011).

O Guia de Livros Didáticos acompanhou o Programa e também sofreu mudanças ao longo do tempo. Por exemplo, em sua primeira publicação, o Guia incluiu todos os livros que reuniram qualidades suficientes para serem recomendados (com ou sem ressalvas). Com base nesse Guia:

[...] os professores teriam condições mais adequadas para a escolha do livro que julgavam mais apropriado a seus pressupostos, às características de seus alunos, às diretrizes do projeto político-pedagógico de sua escola. Poderiam, inclusive, optar por adotar um livro que, embora não recomendado pelo MEC, tivesse tido sua inscrição aceita pelo PNLD (e para isso receberam, ao lado do Guia, um Catálogo com a relação de todos os livros que não foram excluídos no processo de avaliação). Só não puderam escolher livros que - em razão de apresentarem preconceito, discriminação, erro conceitual grave - foram excluídos do Programa Nacional do Livro Didático (BATISTA, 2003, p. 32). 
Em 1997, foi publicado um único volume do Guia, onde constavam as resenhas dos livros, agora "recomendados", "recomendados com ressalvas" e "recomendados com distinção", como já mencionado. Nessa edição, os livros não-recomendados foram apenas relacionados ao final do Guia (BATISTA, 2003). Em 2000, foi publicado o Guia de Livros Didáticos do PNLD 2000/2001, que apresentava resenhas dos livros recomendados (recomendados com ressalvas, recomendados, recomendados com distinção). E, assim, entre mudanças e evoluções, os Guias de Livros Didáticos foram sendo lançados ao longo do tempo.

O Decreto no 9.099, de 18 de julho de 2017, alterou a composição das comissões que avaliam as obras e ampliou o escopo de materiais didáticos que podem ser comprados e distribuídos pelo PNLD. Desse modo, as ações de aquisição e distribuição de livros didáticos e literários, anteriormente contempladas pelo PNLD e por outros programas, foram consolidadas em um único programa. Além disso, antes do referido decreto, os livros didáticos eram "renovados de três em três anos, alternando-se a oferta de livros destinados a cada um dos segmentos do Ensino Fundamental ( $1^{\mathrm{a}}$ a $4^{\mathrm{a}}$ séries e $5^{\mathrm{a}}$ a $8^{\mathrm{a}}$ séries)" (COSTA VAL, 2009, p. 14), Ensino Médio e Educação de Jovens e Adultos. A partir de agora, o PNLD - que, inclusive, tem sua nomenclatura alterada naquele decreto para "Programa Nacional do Livro e do Material Didático" -, será executado em ciclos de quatro anos e não mais de três.

Este decreto possibilitou, ainda, que as redes de ensino, por intermédio da secretaria de educação, definissem qual modelo de escolha as escolas de sua rede irão adotar. São três modelos de escolha: a) Material único para cada escola; b) Material único para cada grupo de escolas; c) Material único para toda a rede. Este se constitui em um ponto bastante polêmico nessa alteração, pois as redes municipais e estaduais também poderão escolher os livros que serão utilizados em todas as escolas, o que significa que as redes terão mais poder de decisão sobre as escolhas pedagógicas, tendo em vista que, até então, a escolha do material era de responsabilidade dos professores e de cada escola.

Mantovani (2009) afirma que, com o passar dos anos, os critérios de avaliação, inicialmente estabelecidos em 1995, também passaram por modificações, sendo aperfeiçoados, mas mantendo o fio condutor que deu sentido ao conjunto inicial. A pesquisa de Mendes (2017) buscou investigar, ao longo do tempo, mudanças e permanências nos critérios de avaliação utilizados pelo PNLD no que concerne ao ensi- 
Estephane

Priscilla dos

Santos Mendes

Ana Cláudia

Rodrigues

Gonçalves

Pessoa no de oralidade no ciclo de alfabetização. Para isso, a autora analisou diferentes edições do Guia de Livros Didáticos do PNLD, publicados entre 1998 e 2016. Como permanência, Mendes (2017) identificou que os critérios estão relacionados, principalmente, à adequação dos gêneros orais a diferentes situações comunicativas, à exploração das relações entre as modalidades oral e escrita da língua e ao uso da língua falada na interação em sala de aula. Como mudança, a referida autora identificou que os critérios passaram a ser mais específicos, atendendo a diferentes dimensões do trabalho com oral, o que resultou numa ampliação significativa das categorias contempladas ao longo dos anos nas diferentes edições do Guia.

Os resultados deste estudo apontaram para a existência de 228

diversidade desses critérios, contemplando, assim, diferentes dimensões do oral enquanto objeto de ensino. Um aspecto importante a ser considerado é o aumento e a diversificação desses critérios de um Guia para o outro. De acordo com a autora, esse movimento parece estar relacionado a uma importância maior dada à oralidade enquanto objeto de ensino, ao longo do tempo, o que impulsiona os livros didáticos a dar mais espaço ao trabalho com esse eixo, contemplando suas diferentes dimensões. Nesse sentido, é objetivo do presente estudo, analisar o eixo de ensino oralidade no PNLD 2019. O quadro 1 apresenta algumas características gerais dos Guias de Livros Didáticos entre os anos de 1998 e 2019:

\section{Quadro 1 - Guias do PNLD (1998 - 2019) características gerais}

\begin{tabular}{|c|c|c|}
\hline Guias & Séries/anos & Qtd. De Livros Aprovados \\
\hline 1998 & Alfabetização & 22 livros \\
\hline $2000 / 2001$ & Alfabetização & 22 livros \\
\hline 2004 & Alfabetização & 28 livros \\
\hline 2007 & Alfabetização & 47 livros \\
\hline 2010 & $1^{\circ}$ e $2^{\circ}$ anos & 19 coleções \\
\hline 2013 & $1^{\circ}$ a $3^{\circ}$ anos & 28 coleções \\
\hline 2016 & $1^{\circ}$ a $3^{\circ}$ anos & 21 coleções \\
\hline 2019 & $1^{\circ}$ a $5^{\circ}$ anos & 13 coleções \\
\hline
\end{tabular}

Fonte: Guias de Livros Didáticos do PNLD 
No que se refere ao Guia do Livro Didático, trata-se de um documento direcionado aos professores e às escolas para orientar a escolha das obras selecionadas pelo PNLD. Nele são explicitados os princípios e critérios específicos do processo de avaliação, feitos comentários sobre as obras avaliadas, apresentado o modelo de ficha de avaliação utilizado para análise das coleções e/ou livros didáticos, além de conter as resenhas das obras classificadas.

A edição do Guia 1998, diferente das edições posteriores, não traz um bloco voltado para o trabalho com oralidade. O Guia 2000/2001 apresenta 2 (dois) critérios relativos ao trabalho com a linguagem oral. A edição 2004 apresenta 4 (quatro) critérios referentes ao ensino da linguagem oral. Tais critérios, que aparecem em um bloco intitulado "Oralidade", contemplam o uso da língua falada nas interações em sala

O tratamento da oralidade no programa nacional do livro didático 2019 de aula, a exploração de semelhanças e diferenças entre a língua oral e escrita, além da abordagem e valorização da variação e a heterogeneidade linguísticas, bem como o desenvolvimento das capacidades envolvidas nos usos do oral em situações formais/públicas. Percebe-se que, de modo geral, o conjunto de critérios apresentados na edição de 2004 é mais geral, não delimitando/especificando dimensões do trabalho com a língua oral.

O Guia de 2007 apresenta 5 (cinco) critérios relativos ao trabalho com a oralidade, com um diferencial em relação às outras edições, pois são levados em consideração, nesse Guia, o trabalho com as linguagens oral e escrita em um mesmo bloco, intitulado "Linguagem Oral e Escrita", com um total de 8 (oito) critérios. No caso da oralidade, são contemplados o uso da linguagem oral em situações escolares, assim como a exploração das diferenças e semelhanças entre a linguagem oral e escrita, além da variação linguística oral e escrita. Contempla, ainda, a argumentação e justificativa de opiniões, além da produção de textos orais em longos turnos. Esse Guia também avaliou apenas 1 (um) livro destinado ao primeiro ano do ciclo de alfabetização

Com 5 (cinco) critérios no bloco "Critérios Relativos ao Trabalho com a Linguagem Oral", o Guia de 2010 retoma a preocupação com a presença de gêneros orais diversos (critério presente no Guia 2000/2001), além do desenvolvimento das "capacidades envolvidas nos usos do oral em situações formais/públicas" (critério presente no Guia 2004). Essa edição de 2010 ainda apresenta critérios já citados em Guias anteriores, como o uso da linguagem oral na interação de sala de aula, 
Estephane

Priscilla dos

Santos Mendes

Ana Cláudia

Rodrigues

Gonçalves

Pessoa

230

a exploração das diferenças e semelhanças que se estabelecem entre a linguagem oral e escrita e a abordagem e valorização da variação e heterogeneidade linguísticas.

O Guia 2013 é o que mais apresenta critérios para o ensino de oralidade: 11 (onze) critérios. Além dos que já foram citados em Guias anteriores, leva-se em consideração o estímulo ao desenvolvimento da escuta atenta, a orientação para a retextualização, orientação para a construção do plano textual dos gêneros orais e a discussão quanto à escolha do registro de linguagem adequado à situação. Há, também, a preocupação com a presença de preconceitos associados às variedades orais. Outra diferença com relação aos Guias anteriores é a orientação para o uso de recursos audiovisuais como auxiliares à produção oral. A partir da edição de 2013, foram avaliadas coleções de livros didáticos contendo 3 (três) volumes, voltados para as turmas de $1^{\circ}$ ao $3^{\circ}$ ano do Ensino Fundamental. A edição de 2016, com 8 (oito) critérios em seu bloco "Oralidade: o que a coleção propõe para o ensino de oralidade?", apresenta uma diminuição de 3 (três) critérios com relação à edição anterior. $\mathrm{E}$ os critérios que permaneceram não apresentam diferenças significativas. No entanto, nessa última edição, foi incluído um critério específico para a exploração da oralização da escrita, por meio de leitura expressiva, encenação, declamação de poemas, jograis, dente outros.

Podemos identificar, desse modo, a existência de uma quantidade razoável de critérios relacionados à oralidade e à diversidade desses critérios, contemplando, assim, diferentes dimensões do oral enquanto objeto de ensino. Outro ponto que chama atenção é o aumento desses critérios relativos à oralidade de um Guia para o outro, por exemplo, o Guia de 2000/2001 apresenta apenas 2 (dois) critérios no bloco oralidade, enquanto o de 2016 indica 8 (oito) critérios para esse mesmo bloco (vale ressaltar que, em 2013, foram 11 (onze) critérios especificamente para a oralidade).

\section{O eixo oralidade no PNLD 2019}

Como resultado das mudanças geradas a partir do decreto $\mathrm{n}^{\circ}$ 9.099, de 18/07/17, o Guia dos Livros Didáticos de 2019 apresentou inúmeras mudanças em relação às edições anteriores: o PNLD 2019 traz o primeiro ciclo de materiais didáticos alinhados à Base Nacional Comum Curricular (BNCC); todas as obras dos anos iniciais do Ensino Fundamental são consumíveis; a obrigatoriedade na escolha de uma mesma coleção do $1^{\circ}$ ao $5^{\circ}$ ano, dentre outras. 
O fato do PNLD 2019 já aparecer atrelado à BNCC é um aspecto que já pode indicar mudanças no que diz respeito à proposta do ensino do oral, pois, diferentemente de outros documentos e orientações oficiais, os gêneros orais mais formais e públicos são indicados mais explicitamente apenas a partir do $3^{\circ}$ ano. Nos $1^{\circ}$ e $2^{\circ}$ anos consideram-se principalmente as situações de comunicação mais comuns ao cotidiano das crianças. Em alguns itens, parece haver um esforço de garantir uma progressão, estabelecendo, para isso, habilidades muito rudimentares, considerando-se a faixa etária para esse nível de ensino. Há uma ênfase nos gêneros orais informais ou mais comuns ao cotidiano dos aprendizes, tais como conversar com o colega, cantar cantigas e canções, recitar parlendas, recontar histórias. Desse modo, muitas das habilidades propostas na BNCC não contemplam aspectos fundamentais da produção

O tratamento da oralidade no programa nacional do livro didático 2019 de gêneros orais mais formais, que demandam planejamento e monitoramento mais consciente da fala. Sendo assim, a BNCC traz retrocessos e poucos avanços em relação ao ensino da oralidade, nos anos iniciais do Ensino Fundamental.

O Guia 2019 confirma que a aprendizagem da língua considera a existência de duas modalidades: oral e escrita, e que há um contínuo entre ambas. Sendo assim, constitui-se enquanto meta de trabalho (para o referido documento) com a Língua Portuguesa no Ensino Fundamental que o aluno: leia e desenvolva a escuta, construindo sentidos coerentes para textos orais e escritos; escreva e fale, produzindo textos adequados a diferentes situações de interação; aproprie-se de conhecimentos e recursos linguísticos - textuais, discursivos, expressivos e estéticos que contribuam para o uso adequado da língua oral e da língua escrita na diversidade das situações comunicativas de que participam (BRASIL, 2018). Com o objetivo de atender a multiplicidade de modalidades e usos da língua escrita e da língua oral, e mantendo o texto como centro de todo o trabalho com a língua, o PNLD, assim como a BNCC, estrutura o trabalho com a Língua Portuguesa no Ensino Fundamental a partir de cinco eixos organizadores.

No que se refere ao eixo de Oralidade, foco deste artigo, o Guia 2019 reforça a ideia de que as crianças desenvolvem e praticam a oralidade de forma natural e espontânea fora da escola, através de interações familiares e sociais. Entretanto, na escola, a oralidade torna-se objeto de conhecimento (características, usos, diferenças em relação à língua escrita) e objeto de desenvolvimento de habi- 
Estephane

Priscilla dos

Santos Mendes

Ana Cláudia

Rodrigues

Gonçalves

Pessoa

232

lidades de uso diferenciado em situações que requerem diferentes graus de formalidade ou atendimento a convenções sociais. Desse modo, no Guia 2019,

o eixo Oralidade inclui conhecimentos sobre as diferenças e se-
melhanças entre língua oral e língua escrita e os usos adequados
da oralidade nas mais diversas interações comunicativas for-
mais e convencionais. Esse eixo inclui também o conhecimento
das variedades linguísticas da língua oral e a criação de uma ati-
tude de respeito frente a essas variedades, desenvolvendo uma
atitude fundamental para o enfrentamento e desconstrução de
preconceitos linguísticos (BRASIL, 2018, p. 14-15).

Esse trabalho com variações linguísticas e relações entre fala e escrita se constitui enquanto uma importante dimensão de ensino do oral, pois permite aos alunos realizar descrições sobre as diferentes formas dialetais e compreender quais fatores provocam essas diferenças nas falas, destacando, ainda, a relação da fala com a escrita, o que impulsiona a busca pelas semelhanças e diferenças entre os gêneros orais e escritos.

A oralidade enquanto objeto de ensino pode partir das práticas orais do cotidiano dos aprendizes, mas não deve se limitar a elas. É preciso, pois, que o ensino de oralidade se centre também nas situações de comunicação pública formal, tendo em vista que "o papel da escola é levar os alunos a ultrapassar as formas de produção oral cotidianas para confrontar com outras formas mais institucionais, mediadas, parcialmente reguladas por restrições exteriores" (DOLZ e SCHNEUWLY, 2004, p. 147). Sendo assim, é importante que os livros didáticos apresentem propostas de atividades com gêneros orais da esfera pública e formal, além das atividades voltadas para situações mais informais de uso da oralidade.

Em relação aos critérios eliminatórios específicos para a avaliação do livro de língua portuguesa no que se refere ao eixo oralidade, levou-se em conta, de acordo com o Guia 2019, o tratamento dado ao desenvolvimento das práticas de produção de textos orais; ao planejamento da fala pública; ao conhecimento das variedades linguísticas da língua oral e à construção da atitude de respeito a essas variedades, de modo que se evitem preconceitos linguísticos (BRASIL, 2018). 
Ao realizar um "balanço" das coleções aprovadas, o Guia 2019 afirma que o desenvolvimento da oralidade está bem presente e de forma diversificada nas coleções. No entanto, as atividades de oralidade estão relacionadas diretamente aos eixos de leitura e escrita. O documento ainda ressalta que as atividades relacionadas ao desenvolvimento da oralidade estão presentes, de modo geral, no início de cada unidade através "da apresentação de imagens acompanhadas de perguntas orientadoras de um debate, contribuindo para o desenvolvimento tanto das habilidades de escuta quanto da articulação da própria fala" (BRASIL, 2018, p. 27). Verificou-se, ainda, um certo predomínio de atividades de oralização de textos escritos, como declamações de poemas, parlendas, jograis, dentre outros.

Leal, Brandão e Lima (2012) apontam ainda que a oralização dos

O tratamento da oralidade no programa nacional do livro didático 2019 textos escritos se situa na intersecção entre a oralidade e a leitura, pois a fluência em leitura, para as referidas autoras, envolve habilidades de comunicação oral. Nesse sentido, Dolz e Schneuwly (2004) apontam que recursos próprios da oralidade são mobilizados no processo de oralização do escrito, pois treinar a fala envolve aspectos relacionados à altura da voz, velocidade e gerenciamento de pausas nas apresentações, assim como aspectos da retórica, da gestualidade e da cinestesia. Desse modo, envolvem a tomada de consciência no que se refere à importância da voz, do olhar, da atitude corporal, dentre outros aspectos, em função de um determinado gênero ou evento comunicativo.

Concordamos com os autores e autoras agora citados, ao considerarmos a leitura em voz alta enquanto uma dimensão do oral na interface com a escrita, principalmente no que se refere ao ensino de oralidade no Ciclo de Alfabetização, no qual as relações entre o oral e o escrito são tomadas também como objeto de ensino do ponto de vista da representação (notação) das partes sonoras das palavras. Para além desse aspecto, as crianças precisam aprender elementos básicos para se comunicar oralmente e por escrito em diferentes situações.

Dessa forma, acreditamos na importância de, desde o Ciclo de Alfabetização, abordar elementos relacionados à altura da voz, velocidade, atitude corporal, fluência nas palavras e nas pausas, dentre outros aspectos, desde que esse trabalho de oralização do escrito esteja acompanhado do trabalho com as outras dimensões do oral.

No que se refere às resenhas, até 2016, elas estavam organizadas/ separadas nos Guias: de $1^{\circ}$ ao $3^{\circ}$ ano - Resenhas de Letramento e alfabe- 
Estephane

Priscilla dos

Santos Mendes

Ana Cláudia

Rodrigues

Gonçalves

Pessoa tização; de $4^{\circ}$ e 5ํano - Resenhas de Língua Portuguesa. No PNLD 2019, as resenhas contemplam conjuntamente os cinco anos (Anos Iniciais do Ensino Fundamental), sem a divisão/organização por ciclos, como anteriormente era feito.

Outra mudança nesta edição é a ficha de avaliação, que está mais extensa do que nas edições anteriores. Não está organizada por eixo de ensino, como nas outras edições, e sim por ano e por pontos trazidos da BNCC. Essa mudança não traz nenhum avanço significativo para essa nova versão do Guia, inclusive fica difícil visualizar o que de fato se coloca como critério para cada eixo. Acreditamos que essa organização se fez necessária, pois, na BNCC, as habilidades referentes a cada ano do Ensino Fundamental, nem sempre se repetem e são "ampliadas/aprofundadas" a cada ano, há uma ideia de progressão nessas habilidades, mas, como já mencionamos, essa progressão também não acontece de maneira significativa, e sim de forma bastante rudimentar e limitada.

Para exemplificar, o quadro 2 traz a sistematização dos critérios presentes na Ficha de Avaliação do Guia 2019 para o eixo oralidade nos livros didáticos de Língua Portuguesa para o $1^{\circ}$ ano do Ensino Fundamental, a partir dos objetos de conhecimento e habilidades da BNCC. 


\section{Quadro 2 - Critérios de Avaliação do Eixo Oralidade no PNLD 2019 - Língua Portuguesa (1ํano)}

\begin{tabular}{|c|}
\hline $1^{o}$ ano \\
\hline $\begin{array}{l}\text { Interação discursiva/intercâmbio oral no contexto escolar. Constituição da identidade } \\
\text { psicossocial, em sala de aula, por meio da oralidade (EF01LP01). Expressar-se, em si- } \\
\text { tuações de intercâmbio oral, com autoconfiança (sem medo de falar em público), para } \\
\text { explorar e apresentar informações, esclarecer dúvidas, trocar ideias, propor, criar ou } \\
\text { engajar-se em jogo ou brincadeira. }\end{array}$ \\
\hline $\begin{array}{l}\text { Interação discursiva/intercâmbio oral no contexto escolar. Regras de convivên- } \\
\text { cia em sala de aula (EF01LP02 }{ }^{2} \text { ). Escutar, com atenção e compreensão, instruções } \\
\text { orais, acordos e combinados que organizam a convivência em sala de aula. }\end{array}$ \\
\hline $\begin{array}{l}\text { Funcionamento do discurso oral. Características da conversação espontânea } \\
\text { (EF01LP03). Participar de conversação espontânea, reconhecendo sua vez de falar e de } \\
\text { escutar, respeitando os turnos de fala e utilizando fórmulas de cortesia (cumprimentos } \\
\text { e expressões como "por favor", "obrigado(a)", "com licença" etc.), quando necessário. }\end{array}$ \\
\hline $\begin{array}{l}\text { Funcionamento do discurso oral. Aspectos não linguísticos (paralinguísticos) no ato da } \\
\text { fala (EF01LP04). Identificar aspectos não linguísticos (paralinguísticos) presentes no ato } \\
\text { de fala (tom da voz e movimentos corporais) como parte do significado do que é dito. }\end{array}$ \\
\hline $\begin{array}{l}\text { Estratégias de escuta de textos orais em situações específicas de interação. Procedi- } \\
\text { mentos de escuta de textos (EF01LP05). Recuperar assuntos e informações pontuais em } \\
\text { situações de escuta formal de textos. }\end{array}$ \\
\hline $\begin{array}{l}\text { Produção de textos orais em situações específicas de interação. Relato oral (EF01LP06). } \\
\text { Relatar experiências pessoais de seu cotidiano, em sequência cronológica e nível de } \\
\text { informatividade adequado. }\end{array}$ \\
\hline
\end{tabular}

Fonte: Guia PNLD 2019 (BRASIL, 2018, p. 168-169).

Como observamos no quadro 1 , os critérios para o $1^{\circ}$ ano buscam o desenvolvimento de habilidades voltadas essencialmente para o uso do oral em situações cotidianas. Concordamos que essas situações de comunicação também contribuem para o desenvolvimento do eixo oralidade e devem ser valorizadas nas práticas de ensino, pois contribuem de forma bastante positiva no desenvolvimento de distintas dimensões da oralidade.

No entanto, acreditamos que as crianças podem ter contato com gêneros formais e públicos já no $1^{\circ}$ ano, como uma introdução ao trabalho com o oral, a ser consolidado nos anos posteriores, como é possível identificar na pesquisa de Nascimento (2009). Na pesquisa, os resultados apontaram, de modo geral, que habilidades do oral podem ser desenvolvidas a partir de sequências didáticas em que o gênero oral é tomado como objeto de ensino. Nesse sentido, é preciso que, desde cedo, os gêneros orais públicos formais estejam presentes e sejam ensi-

2 Códigos referentes às habilidades citadas na BNCC. 
Estephane

Priscilla dos

Santos Mendes

Ana Cláudia

Rodrigues

Gonçalves

Pessoa

236

nados, auxiliando os alunos a desenvolver capacidades orais adequadas a diferentes situações de comunicação. Dentro dessa perspectiva, é importante pensar se os livros didáticos podem contribuir com o ensino da oralidade.

Os critérios de avaliação do PNLD 2019 se relacionam, geralmente, à participação nas interações orais em sala de aula, argumentação sobre diferentes acontecimentos, escuta atenta e compreensiva, respeito aos turnos de conversação (em situações formais e informais), gêneros textuais do discurso oral (conversação, entrevista, debate, noticiário, dentre outros), produção de textos orais em situações específicas de interação (jornal falado e entrevista, por exemplo), identificação de informações, opiniões e posicionamentos em situações formais de escuta (exposições, palestras, noticiário radiofônico ou televisivo etc.), diferenciação do texto falado em relação ao texto escrito, dentre outros.

O que percebemos é que não há avanço/mudança nos critérios para o ensino de oralidade. Por exemplo, a edição de 2016 traz como critérios para os três primeiros anos: exploram gêneros orais adequados a situações comunicativas diversificadas (entrevista, jornal falado, apresentação de trabalho, debate, etc.); exploram a oralização da escrita (leitura expressiva, encenação, declamação de poemas, jograis, etc); estimulam o aluno a desenvolver a capacidade da escuta atenta e compreensiva; exploram as relações entre as modalidades oral e escrita da língua em diferentes práticas sociais e em diferentes gêneros; orientam a construção do plano textual dos gêneros orais (critérios de seleção e hierarquização de informações, padrões de organização geral, recursos de coesão); discutem e orientam a escolha do registro de linguagem adequado à situação (prosódia, recursos de coesão, seleção vocabular, recursos morfossintáticos etc.), e orientam o uso de recursos audiovisuais como auxiliares à produção oral (cartaz, painel, projetor, entre outros). Esses critérios no Guia 2016 são postos de forma clara e objetiva em um bloco específico para o eixo oralidade, destinado às coleções de $1^{\circ}$ ao $3^{\circ}$ ano, o que não acontece na edição de 2019.

Nas edições anteriores, não fica claro quais critérios devem ser contemplados em cada ano, e nem como deve acontecer a progressão. Os critérios são postos em blocos para cada eixo, como já mencionamos. Há, de certo modo, uma vantagem na forma como está organizada a ficha de avaliação do Guia 2019: a delimitação por ano nos permite visualizar o que o documento exige para cada ano e como a progressão 
acontece. No entanto, não há uma divisão mais específica dos eixos, o que impede, de certo modo, visualizar o que se exige como critério para o ensino específico do oral.

Como não há um bloco específico para oralidade na ficha, é possível identificar dimensões do oral sendo mobilizadas em critérios aparentemente de outros eixos. Por exemplo, ao tratar de objetos de conhecimento referente ao eixo texto literário, há menção ao trabalho com oralidade:

O texto literário no contexto sociocultural, dimensão social e estética do texto literário (EF02LP47): compartilhar em sala de aula textos de tradição oral pesquisados na família e na comunidade (em versos cantigas de roda, adivinhas, parlendas, quadrinhas, trava-línguas etc. e em prosa contos populares, fábulas,

O tratamento da oralidade no programa nacional do livro didático 2019 mitos, lendas etc.) (BRASIL, 2018, p. 186).

Essa presença de dimensões do oral em critérios voltados para outros eixos de ensino poderia se constituir enquanto ponto positivo dessa nova versão, haja vista que há muito já se discute sobre a necessidade de articular os diferentes eixos de ensino no trabalho pedagógico, de forma que sejam consideradas as especificidades de cada eixo, ao longo do processo de ensino-aprendizagem. No entanto, são justamente essas especificidades que parecem ser pouco delimitadas e exploradas na ficha de avaliação e no documento como um todo.

\section{Considerações finais}

Este artigo teve como objetivo analisar como se apresenta o eixo de ensino oralidade no PNLD 2019 e quais as principais mudanças do Guia 2019 em relação às edições anteriores-no que concerne ao trabalho com o oral nos Livros Didáticos. Identificamos, de modo geral, que os critérios presentes no Guia 2019 não trazem nenhuma grande inovação ou avanço no que concerne ao eixo oralidade nos $1^{\circ}$ e $2^{\circ}$ ano. Pelo contrário, consideram-se principalmente as situações de comunicação mais comuns ao cotidiano das crianças. Os gêneros orais mais formais e públicos são indicados mais explicitamente apenas a partir do $3^{\circ}$ ano em diante, o que não acontecia nas edições anteriores. Em alguns itens, parece haver um esforço de garantir uma progressão, estabelecendo, para isso, habilidades muito básicas, considerando-se a faixa etária para esse nível de ensino. 
Em relação às edições anteriores, o Guia 2019 traz mudanças na estrutura da ficha de avaliação e das resenhas, porém pouco avança no conteúdo. Nas edições anteriores, os critérios são postos de forma clara

Estephane e objetiva em um bloco específico para o eixo oralidade, o que é impor-

Priscilla dos tante por apresentar maior clareza naquilo que é necessário ser trabaSantos Mendes lhado nesse eixo de ensino.

Na edição de 2019, como não há um bloco específico para oralidaAna Cláudia de na ficha, é possível identificar dimensões do oral sendo mobilizadas Rodrigues em critérios aparentemente de outros eixos. Desse modo, a oralidade Gonçalves acaba por ficar, na maioria dos casos, em função dos outros eixos do Pessoa ensino, não aparecendo como objeto de ensino autônomo e complexo.

\section{REFERÊNCIAS}

ALVES, Irene de Barcelos. Entre regulação e persuasão: a política curricular para o livro didático de geografia dos anos iniciais do ensino fundamental no PNLD 2010. Dissertação (Mestrado em Educação) - Universidade Federal do Rio de Janeiro, Rio de Janeiro, 2011.

ÁVILA, Ewerton; NASCIMENTO, Cláucia; GOIS, Siane. Ensino de oralidade: revisitando documentos oficiais e conversando com professores. In: LEAL, Telma Ferraz; GOIS, Siane. A oralidade na escola: a investigação do trabalho docente como foco de reflexão. Belo Horizonte: Autêntica, 2012.

BATISTA, Antônio Augusto Gomes. Avaliação dos livros didáticos: para entender o programa nacional do livro didático (PNLD). In: ROJO, Roxane; BATISTA, Antônio Augusto Gomes (orgs). Livro didático de língua portuguesa, letramento e cultura da escrita. Campinas, SP: Mercado de Letras, 2003.

BRASIL/MEC. Guia de Livros Didáticos 1998: $1^{\mathrm{a}}$ a $4^{\mathrm{a}}$ séries. PNLD, Brasília, 1997.

BRASIL/MEC. Guia de Livros Didáticos 2000/2001: $1^{\mathrm{a}}$ a $4^{\mathrm{a}}$ séries Língua Portuguesa. PNLD, Brasília, 1999. 
BRASIL/MEC. Guia de Livros Didáticos 2004: $1^{\text {a a }} 4^{\text {a }}$ séries - Língua Portuguesa. PNLD, Brasília, 2003.

BRASIL/MEC. Guia do livro didático 2007: alfabetização: séries/ anos iniciais do ensino fundamental. PNLD, Brasília, 2006.

BRASIL/MEC. Guia de livros didáticos 2010: Letramento e Alfabetização/Língua Portuguesa. PNLD, Brasília: 2009.

BRASIL/MEC. Guia de livros didáticos 2013: letramento e alfabetização e língua portuguesa. PNLD, Brasília, 2012.

O tratamento da oralidade no programa nacional do livro didático 2019

BRASIL/MEC. Guia de livros didáticos 2016: Alfabetização e letramento e língua portuguesa: ensino fundamental anos iniciais. PNLD, Brasília: 2015.

BRASIL/MEC. Guia de livros didáticos 2019: Língua Portuguesa. PNLD, Brasília: 2018.

BOTLER, Laís Maria Avares Rosal. Gêneros orais e ensino de língua portuguesa: concepções e práticas. Dissertação (Mestrado em Educação) - Universidade Federal de Pernambuco, Recife, 2013.

CELESTINO, R. S.; LEAL, T. F.; BRANDÃO, A. C. P.; ANDRADE, R. B. L. A Oralidade e Argumentação nas práticas de professoras de $4^{a}$ série. In: XVI Seminário de Leitura no Brasil. Anais do XVI Seminário de Leitura no Brasil. Campinas (SP), 2007.

CELESTINO, Rafaela Soares; LEAL, Telma Ferraz. o debate como objeto de ensino: interdisciplinaridade e desenvolvimento de habilidades argumentativas. 2008. TCC (Curso de Pedagogia) - Universidade Federal de Pernambuco, Recife, 2008.

COSTA-MACIEL, Débora Amorim Gomes da. Livros didáticos de língua portuguesa: propostas didáticas para o ensino do oral. Dissertação (Mestrado em Educação) -Universidade Federal de Pernambuco, Recife, 2006. 
COSTA-MACIEL, Débora Amorim Gomes da; BARBOSA, Maria Lúcia Ferreira de Figueiredo. "Ah, eu acho a oralidade muito importantíssima, meu deus!” A propósito da prática docente no ensino da

Estephane oralidade. Anais da 35ª Reunião Anual da Anped. Porto de Gali-

Priscilla dos nhas - PE, 2012.

Santos Mendes

Ana Cláudia livros didáticos e práticas pedagógicas. Belo Horizonte: Autêntica, Rodrigues CEALE/FAE/UFMG, 2009.

Gonçalves

Pessoa DOLZ, Joaquim; SCHNEUWLY, Bernard. Gêneros e progressão em expressão oral e escrita: elementos para reflexões sobre uma experiência suíça (francófona). In: SCHNEUWLY, Bernard; DOLZ, Joaquim. Gêneros orais e escritos na escola. Tradução e organização: ROJO, Roxane; CORDEIRO, Glaís Sales. Campinas, SP: Mercado de Letras, 2004.

DUTRA, Andreia Soares. 0 espaço da oralidade na aula de língua portuguesa: orientação dos PNC e propostas dos livros didáticos. Dissertação (Mestrado em Letras) - Universidade do Estado do Rio de Janeiro, Rio de Janeiro, 2013.

LE GOFF, Jacques. História e Memória. Tradução Bernardo Leitão et al. Campinas, SP: UNICAMP, 1990.

LEAL, Telma Ferraz; GOIS, Siane. A oralidade na escola: a investigação do trabalho docente como foco de reflexão. Belo Horizonte: Autêntica, 2012.

LEAL, Telma Ferraz; BRANDÃO, Ana Carolina Perrusi; LIMA, Juliana de Melo. A oralidade como objeto de ensino na escola: o que sugerem os livros didáticos?. In: LEAL, Telma Ferraz; GOIS, Siane (orgs). A oralidade na escola: a investigação do trabalho docente como foco de reflexão. Belo Horizonte: Autêntica, 2012.

MAGALHÃES, Tânia Guedes. Concepção de oralidade: a teoria nos PCN no PNLD $\mathrm{x}$ a prática nos livros didáticos. Tese (Doutorado em Letras) -Universidade Federal Fluminense, Niterói, 2007. 
MANTOVANI, Kátia Paulilo. o programa nacional do livro didático PNLD: impactos na qualidade do ensino público. Dissertação (Mestrado em Geografia Humana) - Universidade de São Paulo, São Paulo, 2009.

MARCUSCHI, Luiz Antônio. Oralidade e ensino de língua: uma questão pouco "falada". In: DIONISIO, Angela Paiva; BEZERRA, Maria Auxiliadora (Orgs.). 0 livro didático de português: múltiplos olhares. 3. ed. Rio de Janeiro: Lucerna, 2005.

MENDES, Estephane Priscilla dos Santos. A oralidade no Programa Nacional do Livro Didático (1998-2016): critérios de avaliação e perfil dos livros de alfabetização aprovados. Dissertação (Mestrado em Educação Contemporânea) - Pós-Graduação em Educação Contemporânea, Universidade Federal de Pernambuco, Caruaru, 2017.

NASCIMENTO, Maria Tereza F. G. A exposição oral na Educação Infantil: contribuições para o ensino e aprendizagem dos gêneros orais na escola. Dissertação (Mestrado em Educação) - Pós-Graduação em Educação, Universidade Federal de Pernambuco, Recife, 2009.

ROJO, Roxane; BATISTA, Antônio Augusto Gomes. Livro didático de língua portuguesa, letramento e cultura da escrita. Campinas, SP: Mercado de Letras, 2003.

SANTOS, Josileide Teófilo. o tratamento da Oralidade no Livro Didático. Universidade Estadual da Paraíba. Trabalho de Conclusão de Curso. Licenciatura em Letras, 2013.

SCHNEUWLY, Bernard. Palavra e ficcionalização: um caminho para o ensino da linguagem oral. In: SCHNEUWLY, Bernard; DOLZ, Joaquim. Gêneros orais e escritos na escola. Tradução e organização: ROJO, Roxane; CORDEIRO, Glaís Sales. Campinas, SP: Mercado de Letras, 2004.

SOUZA-MACHADO, T. H. As práticas orais na escola: recomendações do livro didático do $1^{\circ}$ ano do ensino fundamental. Domínios de Lingu@gem, v. 7, n. 1, 2013. 
